\section{"To Depart from the Earth with Such Writing": Johannes Kepler's Dream of Reading Knowledge}

ELIZABETH

A. SPILLER

Résumé: Johannes Kepler peut être compris comme représentant du conflit entre l'observation et la lecture qui a défini les théories de la connaissance à la Renaissance. Le constat de nouvelles connaissances est devenu difficile dans la mesure où la lecture et l'observation, actes de voir qui promettaient de nouvelles façons de savoir, s'avéraient concurrentielles l'une avec l'autre. Dans son Somnium (Songe), Kepler théorise un intérêt pour la lecture très typique de l'époque. Les questions concernant la lecture et l'observation qui prêtent une structure aux oeuvres de Kepler plus strictement scientifiques deviennent le sujet du récit du Songe. Tout comme Kepler se sert de la fiction du Songe pour illustrer un système universel qui marginalise l'homme physiquement et marque les limites de la connaissance humaine, il projette aussi un monde et un lieu au delà de ces limites.

Campanella wrote a City of the Sun. What about my writing a "City of the Moon"? Would it not be excellent to describe the cyclopic mores of our time in vivid colors, but in doing so - to be on the safe side - to depart from the earth with such writing and secede to the moon? However, what would such a flight be good for? More in his Utopia and Erasmus in his Praise of Folly ran into trouble and had to defend themselves. Therefore let us leave the vicissitudes of politics alone and let us remain in the pleasant, fresh green fields of philosophy. (Johannes Kepler ${ }^{1}$ )

If I had ascended the very heaven and beheld completely the nature of the universe, and the beauty of the stars, the wonder of it would give me no pleasure, if I did not have you as a friendly reader to tell it to. (Johannes Kepler, citing Cicero, De amicitia ${ }^{2}$ ) 
In a 1623 letter to Matthias Bernegger, Johannes Kepler evokes the larger I political turmoil of earrly seventeenth-century Europe when he describes his decision to write and revise his lunar astronomy in fictional form. Initially a set of theoretical propositions about the moon compiled by Kepler as a university student, the Dream was a work that Kepler revised many times before it was finally published after his death in $1634 .{ }^{3}$ The first fictional work to see the earth from a specifically Copernican perspective, Kepler's sometimes curious and often compelling narrative contains a truly "vivid" description of how the earth would appear when seen from the perspective of the moon. This alternative view of earth is then set inside an elaborate fairy-tale frame, which was annotated, over a period of about ten years, with hundreds of footnotes. ${ }^{4}$ Most readers have identified the Dream as a utopia; indeed, Kepler's appraisal of his possible literary models in his letter to Bernegger is in keeping with claims made by recent critics of the utopia. In his now classic study, Utopics, Louis Marin argues that utopias must be understood less as a verbal description or representation of some "idea" about what society should be like than as a verbal act that is inherently also a political statement. ${ }^{5}$ Elaborating on Marin's conception of the utopia as a "discursive practice," Fredric Jameson has argued that utopias are structured to put conflicting possibilities in relation to one another as a way of textually working out otherwise unresolvable cultural problems. ${ }^{6}$ Marina Leslie's recent reassessment likewise begins with the proposition that utopias are neither "straightforward social blueprint" nor fixed literary genre; they are instead "a complex textual practice enmeshed in a web of historical contingencies."7 While these accounts of utopia as a writing praxis have been powerful, Kepler himself encourages us to understand his Dream in other terms. Unlike More, who makes us consider the writing of the Utopia as a way of doing, Kepler's Dream gives us a way of reading as knowing.

In an influential account of the development of modern philosophy, Richard Rorty has argued that in the seventeenth century "perceptual metaphors" became the dominant figure for knowledge. ${ }^{8}$ Although Plato and Aristotle would have agreed in finding "absurd" the idea of "basing knowledge on appearances," the early modern period made apprehension the foundation for comprehension. ${ }^{9}$ While Rorty is interested in showing how metaphors of sight as knowledge helped to redefine philosophy, confirmation for his claims can be found in the way that the act of seeing was itself being redefined by early modern science. The question of how one might "apprehend" something became increasingly difficult to answer as reading 
and observation - acts of seeing that promised to provide ways of knowing - competed with each other. While early modern scientific writers sometimes dismiss the traditional citing of textual authorities in favor of their own work, Anthony Grafton demonstrates how reading nonetheless remained "the model" for "all complex forms of learning." 10 The citing of "authorities" produced texts that were in some sense a series of readings of earlier works. Observations, by contrast, relied not just on potentially fallible individuals but increasingly on technologies such as the telescope or the pinhole camera, which augmented vision by distorting it. If traditional philology seemed to have no way to get out of the potentially infinite regress of reading, observational practice had no method for transforming its knowledge into texts.

Johannes Kepler can be understood as a figure for the conflict between observation and reading that has come to define modern theories of knowledge. J. V. Field has thus demonstrated how Kepler's emphasis on reading has made subsequent attempts to understand his work difficult. Not only do Kepler's commentaries on his own work reread classical authorities, but they also recast his earlier writings. ${ }^{11}$ Grafton points out that Kepler's work as a whole illustrates in this context "how much the act of reading meant to him." 12 In the Dream Kepler theorizes this interest in reading, which Grafton identifies as being characteristic of the early modern period as a whole. The questions about reading and observing that structure Kepler's more strictly scientific works become the narrative subject of the Dream. Kepler keeps returning to this comparatively insignificant text - revising, restructuring, explaining, adding notes and then notes to those notes - because doing so enables him to think through in narrative form the scientific practices that underlie his other works.

Kepler's Dream follows the convention of earlier utopias in using an elaborate frame narrative to introduce his selenography. In most utopias the frame separates the reader from the ideal world being imagined and thus becomes both a point of entry to an imagined ideal and a barrier ever to realizing that ideal. Reading may in some sense take us from the impossible to the ideal through an imaginative self-projection. ${ }^{13}$ In Kepler's case, the materials which surround his narrative - the frame, footnotes, and a companion volume translation of Plutarch - become a meditation on the act of reading in which we are engaged. Intervening between us and the central text, these materials depict reading as an act of seeing that sometimes confirms but more often conflicts with the kinds of observations produced by the telescope. Making the methods and technologies of the "New Astron- 
omy" a key part of the reader's experience of the text, Kepler thus shows how emphasis on observation transforms reading into a contested practice in the early modern period. As a utopian fiction, the Dream explores the conflict between reading and experience associated with the telescope as a new way of seeing. ${ }^{14}$ The complex structure of Kepler's Dream thus becomes in a critical sense a narrative realization of the act of reading. Following Cicero in emphasizing how he would re-create for his readers the "wonder" and "beauty" in his knowledge of the heavens, Kepler gives us a Dream in which reading is not so much the way to a utopian ideal as it is that ideal.

Kepler's dramatization of this point of view derives from the fact that he never truly doubted the Copernican hypothesis of a heliocentric universe; hence, Kepler did not conceive of the Dream as "proof" of Copernicus. Rather, the Dream is an argument for the Copernican hypothesis that nostalgically projects a utopian world in which seeing and knowing were joined as they apparently had been in the pre-Copernican world. Despite the fact that Kepler claimed that the purpose of the Dream was "to use the example of the moon, to build up an argument in favor of the motion of the earth" (p. 36), this work was of comparatively little scientific importance. Critical discussions of the Dream have generally separated Kepler's presentation of his scientific ideas at the center of the text from the complex textual apparatus that surrounds it. Kepler's readers have thus emphasized the scientific accuracy of his representation of what the earth would look like without fully recognizing how, even in the most apparently scientific sections of this work, Kepler is also indulging in a fantasy world in which mediation and distortion would not interfere with what we see and know. ${ }^{15}$ Understood in this context, Kepler's fantasy about unproblematic knowledge works to solve the challenges set out in the frame narrative.

Kepler seeks this solution not only as a scientist but as a reader. As has often been observed, the final form of the Dream stands in some sense as a correction to misreadings of earlier versions of the text that Kepler believed had led to witchcraft charges being brought against his mother. ${ }^{16}$ After what originally seems to have begun as a business dispute with a neighbor, Katharina Kepler was accused, imprisoned, and threatened with torture as a witch before finally being released in 1621 , almost six years later. ${ }^{17}$ Although Kepler recognized that the neighbor, Ursula Reinbold, herself acted against his mother out of personal animosity, he also believed that erroneous readings of an early version of the Dream had made Reinbold's charges credible 
to others who became involved. For a copy of the 1609 manuscript, given by Kepler to Baron von Volkersdork, had circulated privately, making its way, according to Kepler, from Prague to Leipzig, Tübingen, and ultimately Württemberg. There Kepler's story about the herb seller Fiolxhilde, who called "daemon" creatures down from the skies, produced "chatter" and "malicious gossip" in the barbershops throughout the city (p. 40, n. 8). Part of the problem with Kepler's manuscript was clearly a conflict over reading practices. Where Kepler, sensitive to language of light and dark throughout his Dream selenography, understood allegory as a way of revealing scientific truths under cover, as it were, the barbershop readers interpreted Kepler's fiction simply as a dark story: "those words fell upon minds which were dark within and suspected everything of being dark" (p. 39, n. 8).

Looking back on the misconstruings that produced such difficulties for his mother, Kepler understands not just the publication but the revised form of the Dream as a way to "avenge this dream of mine" in "another punishment for my adversaries" (pp. 40-41, n. 8). While Kepler does refer in passing to what he takes to be misconceptions about the nature of witchcraft on the part of tribunals like the one that tried his mother, his primary focus in the notes is on the kinds of bad reading that led to the charges against her. ${ }^{18}$ Kepler's elaborate, and ever increasing, footnotes initially provide a corrected reading of the allegory of the Dream. While offering a model for a better kind of reading, Kepler's notes also impose an interpretation that preempts further, potentially erroneous readings by others. Recognizing that reading can be not just a means to knowledge but also a way to the kinds of dangerous errors that led to Katharina Kepler's persecution is a key topic of the Dream. In the opening sentences of the revised Dream, Kepler introduces the subject matter that led to the witchcraft charges:

My name is Duracotus. . . . My mother is Fiolxhilde. Her recent death freed me to write, as I had long wished to do. While she lived, she carefully kept me from writing. For, she said, the arts are loathed by many vicious people who malign what their dull minds fail to understand, and make laws harmful to mankind. Condemned by these laws, not a few persons have perished in the chasms of Hekla. (pp. 11-12)

The illiteracy of Kepler's own mother may have contributed the basis for the fictional Fiolxhilde's assertions that the "vicious" and "dull" will misread those things which they do not understand. In Kepler's annotations to the text, however, this first mention of the witch-mother Fiolxhilde critically becomes an allegory about reading and its relationship to the pursuit of truth. Kepler thus glosses this previously controversial passage 
with the "further suggestion" that in Fiolxhilde we see the "mother, Ignorance" who forbids her son "Science" to "reveal to the public the deeply hidden causes of things" (p. 36, n. 4). Kepler almost certainly must have wished for his mother's sake that he had heeded advice like Fiolxhilde's. At the same time, he also recognizes that, whatever the awful consequences were of circulating that early version of the Dream, it is precisely the reluctance to see the truth that allows ignorance and suspicion to flourish. Far from exonerating his mother from witchcraft charges, Kepler suggests that his witch Fiolxhilde is a figure for the symbolic illiteracy that leads to terror and suspicion rather than truth.

Kepler's desire to make amends to his mother through a more truthful kind of reading can be seen in his invocation of Christopher Besold as a reader of the revised Dream. The second of the 223 notes addresses Besold directly:

I have a very old document which you, most illustrious Christopher Besold, wrote with your own hand, when, in the year 1593, on the basis of my essays, you formulated about twenty theses concerning the celestial phenomena on the moon and showed them to Veit Müller, who then regularly presided over the philosophical disputations, with the thought that you would engage in a debate over them if he approved. (p. 32, n. 2)

Besold appears here at the beginning of the text as a way of remembering that he was in some sense the first reader of what became Kepler's Dream. As Kepler indicates, he and Besold were students at the University of Tübingen together. When Kepler under Michael Maestlin's influence first drew up propositions that used the example of the moon to demonstrate various Copernican ideas, Besold was one of the friends with whom Kepler shared his work. For Kepler, the notes that Besold subsequently wrote for a school rhetoric exercise constitute the first "reading" of his work.

As the originary reader, Besold is also Kepler's ideal reader, the kind of reader to whom Kepler implicitly addressed texts such as The Mystery of the Universe (1596, 1621), The New Astronomy (1609), and The Harmony of the World (1619). As Kepler suggests in a 1623 letter to Matthias Bernegger, his Dream was originally intended not simply as a "proof" of the movement of the moon, an epitome of Copernican ideas. Rather, it was written as a compendium of different intellectual problems, directed at different kinds of readers:

I have started to work again on the astronomy of the moon, or rather to elucidate it by remarks. ... there are just as many problems as lines in my writing, which can only be solved astronomically, physically, or historically. But what can one do about this? How 
few people will attempt to solve them? The people wish that this kind of fun, as they say, would throw itself around their necks with cosy arms; in playing they do not want to wrinkle their foreheads. Therefore, I decided to solve the problems myself, in notes, ordered and numbered. ${ }^{19}$

Besold is, in this context, a true reader of Kepler's work: he transformed Kepler's original propositions in his "hand-written" notes into the basis for a disputation that itself offered a way of solving problems and learning the truth. Yet, if Besold appears as the first true reader of Kepler's Dream, the allusion to him also reminds us that Besold read the ultimate and unanticipated consequences of that school exercise. A law student when Kepler first met him, Besold subsequently became a member of the law faculty at the university. As one of the jurists to whom Katharina Kepler's witchcraft trial was eventually referred for a decision, Besold almost certainly read the 128-page defense that Kepler wrote for his mother. ${ }^{20}$ It was the decision of this faculty that finally, after six years, resulted in the charges against Katharina Kepler being dismissed. In this context, Besold represents both the first and the last reader of that earlier, mistaken version of the Dream.

Yet, if Kepler's revisions and annotations to the Dream begin through Kepler's desire to correct the misinterpretations that led to witchcraft charges, Kepler's recasting of his work more critically becomes part of a larger attempt to develop a theory that reflected upon the reading practices informing his scientific work. While Kepler is best known for his use of observational data to construct new star charts and tables, it was of course Tycho Brahe, not Kepler, who did the observing. As a scientific observer, therefore, Kepler in some sense begins as a reader. At the most basic level, Kepler's notoriously bad eyesight and the difficulty he had in obtaining reliable telescopes ensured that his practice of astronomy was not defined in strictly observational terms. As Grafton points out in this context, Kepler relied on written descriptions from other astronomers to provide a visual aid for his observational work. He accordingly uses Girolamo Cardano's “crisp, well-chosen adjectives to compensate for weakness of his own eyesight ... [in seeing] what a comet's tail actually looked like."21

In contrast to the scientific texts which Steven Shapin and Simon Schaffer have described as transforming early modern readers into vicarious observers, readers of the Dream are not observers. ${ }^{22}$ Kepler initially uses a fictional form precisely because he wants to describe something that no one - no matter how good the telescope - could see from earth. Kepler's 
Dream becomes a dream about reading and observation. One day, after reading about the legendary history of Bohemia, the narrator falls asleep and dreams that he is reading another book about a man named Duracotus. A fictional version of Kepler, Duracotus is able to learn about the moon and stars through the discoveries and revelations of a daemon, who shows him a vision of Levania (the moon) that comprises the central part of the text. If Kepler is reading at the outset of the narrative, he is also involved in "watching the stars and the moon" (p. 11). Yet, even as Kepler invokes these two methods of acquiring astronomical knowledge, he rejects them as insufficient, since it is through a dream that he has his vision. His dream in turn replicates the potential conflicts between these acts of observation and reading. In dreaming that he is reading yet another book - one obtained at the Frankfurt book fair - Kepler reminds his readers that this book fair was the best source for new scientific books that were innovative, controversial, or even censored. ${ }^{23}$ Yet, at the same time, this dream about reading is itself presented as a form of astronomical observation: the dream begins with the drowsiness brought on by a late night watching stars and ends with a storm that would have made astronomical observations as well as astronomical dreams impossible (p. 11).

Like Kepler's narrative, Duracotus is also associated with the different forms of reading and observation that define contemporary scientific practice. Duracotus learns not just Danish but modern methods of science when he studies with the astronomer Tycho Brahe at his observatory complex on the island of Hven. Although Kepler never had the opportunity to see the real Uraniborg, his depiction of it in the Dream represents an imaginative and intellectual response to the almost mythological iconography surrounding Brahe's famous and, by the time Kepler came to work with Brahe, lost astronomical castle. As Brahe's detailed description of Uraniborg in the Astronomiae instaurae mechanica (1598) makes clear, Brahe built on Hven what he understood to be an architectural expression of precisely the cosmic order that he hoped Uraniborg would enable him to observe, discover, and record. ${ }^{24} \mathrm{He}$ consequently placed considerable emphasis on the remarkable and expensive instruments that he had made for watching the skies: a large armillary, the great globe inscribed with more than a thousand star positions, and his famous mural quadrant, constructed of solid brass, with a two-meter radius, and permanently affixed to a north-south wall of the castle, among others. Contemporary detractors such as Andreas Libavius, by contrast, suggested that what Brahe understood to be unprecedentedly rigorous obser- 
vation rather involved indulging in an outmoded life of contemplation that contributed little to civic society. ${ }^{25}$ If Uraniborg became a symbol in debate over the shift from a philosophy based on the vita contemplativa to the vita activa in the ways that Owen Hannaway suggests, ${ }^{26}$ Kepler understood the observational activity of Uraniborg as part of a different debate.

Drawing on the representation circulated by Brahe of his observatory and its splendid instruments, Kepler in the Dream depicts the Uraniborg that Duracotus visits as a place that critically combines modern observational techniques with modern reading practices. Following both Brahe's lead in the Astronomiae instaurae mechanica and his own personal interest in Brahe's work, Kepler certainly emphasizes the importance of tools and observations. As Kepler knew from having worked with Brahe at Benetky and in Prague, instruments like the great sphere and armillary made it possible to develop what Kepler praises as the "highly precise method of observation" with which Brahe "fought against the very nature of human vision and emerged victorious" (p. 47, n. 25). ${ }^{27}$ Yet studies at Uraniborg also depended on reading as much as observation: Brahe had an extensive library containing more than two hundred scientific works, a paper mill, and a private printing press, which enabled him to avoid many of difficulties that Kepler faced in getting his works into print. ${ }^{28}$ Kepler's Duracotus as a result learns both by using new observational tools and by reading books: "things which you saw with your own eyes or learned by hearsay or absorbed from books" (p. 14). Uraniborg appears in the frame narrative to the Dream, that is, as the best attempt to integrate reading and observation as the two dominant contemporary means of acquiring scientific knowledge. While some readers have described Brahe's Uraniborg as a realization of a utopian scientific practice, Kepler ultimately looks back on this island haven, not merely as a dream that was lost, but, more importantly, as one that could never be fully achieved in this world. ${ }^{29}$ Despite his training, Duracotus does not acquire his "new knowledge" of the moon through the methods taught at Uraniborg but through a vision from his otherworldly daemon. The purpose of Kepler's elaborate frame narrative, then, is to portray the acts of reading and observation pursued at Uraniborg as important but finally never adequate means of acquiring knowledge.

If the frame narrative introduces the conflict between reading and observation in producing knowledge, the footnotes provide a more extended commentary on these practices. Situating Kepler's work within the historical development of an "analytico-referential" discourse, Timothy Reiss con- 
cludes that "it is almost as though the Dream text posed a constant problem that Kepler eventually sought to elucidate in his notes by the use of an analytical tool developed elsewhere." 30 Although Reiss is speaking in more general terms, the truth of his argument can be seen by comparing the Dream to Kepler's earlier Secret of the Universe. Understanding Kepler's annotation of the Dream requires recognizing how this work provides a kind of textual conclusion to Kepler's Secret. Looking back on his work in 1621, Kepler argued that all of his subsequent writing had developed as "an illustration or a completion" of his first book, The Secret of the Universe. 31 Yet while Kepler's cosmological "discovery" of the shapes of the planetary spheres contained ideas that continued to be a key part of later works, The Secret of the Universe anticipates the Dream less in its intellectual content than in sketching out how Kepler in the Dream connects his reading practices to his astronomical work.

Like the Dream, The Secret of the Universe was a continuing preoccupation of Kepler's. Regarding this 1596 treatise as the most significant of his works, Kepler issued a second edition in 1621. While noting that most writers would rewrite and revise, Kepler instead decided after twenty-five years to reprint the original text, but, as he said, "partly emended, partly explained, and partly confirmed by most remarkable notes." 32 Expressing the distance between the planets as a "Marvelous Proportion," Kepler's Secret used the five Platonic solids (tetrahedron, cube, octahedron, dodecahedron, and icosahedron), successively inscribed within the spheres of the planets, to explain the construction of the universe. ${ }^{33}$ Kepler's subsequent notes both confirm and correct his continuing interest in this theory. Evaluating the 1621 edition, historians have understandably been interested in following Kepler's textual annotations as a guide to the development of his intellectual thought. ${ }^{34}$ Kepler, however, uses the footnotes not just to define his relationship to the ideas of the first edition but, at the same time, to assert his relationship to the text itself. Kepler draws attention to this aspect of the notes when he provides an account in the 1621 preface of his decision not to revise the text more fully. Kepler explains that he chose "the form of edition which is usually adopted in reprinting other people's books" because the original edition had been so widely read that it "should not be thought of as my own, to alter or enlarge at will." 35 Finding that the existence of other readers has in some critical way changed his relationship to his work, Kepler returns to his text as a reader rather than as a writer. In this context, Kepler's 
footnotes give him a way to mark the importance that he attaches to the act of reading.

In the Dream, Kepler continues this practice of annotating his work with a degree of self-consciousness that demonstrates how the Dream is concerned less with what Kepler does than with what he thinks. These notes invoke a wide range of readers, both actual and implied: particular individuals, readers of earlier works, spectators who had witnessed specific astronomical observations. In this respect, the notes reflect Kepler's understanding of the Dream as an encoded text comparable to Galileo's famous astronomical anagrams: the text was full of problems, each to be "solved" by different kinds of readers. While in part reflecting the failure of earlier drafts of this text to attract the ideal readers for whom Kepler intended his cryptic text, the footnotes more significantly become a reflection on the range of Kepler's reading practices. When Kepler explains the illegitimacy of Duracotus, he thus reads his Dream as a kind of medieval allegory in which the "Mother of Science" is Ignorance, the father Reason, who "is quite properly either not known by that mother or concealed by her" (p. 43, n. 10). Kepler relies on numerology to explicate parts of the text ("the Latin words for 'Copernican Astronomy' contain this very number of letters or characters" [p. 51, n. 38]); astrological patterns explain other details (p. 55, n. 43). Kepler demonstrates familiarity with the reading strategies of humanist philology when he provides etymological derivations for his terms: his name for the Levanians, for instance, prompts a commentary on the Hebrew "Lebhana," Greek "Selene, from selas," and Etruscan "Luna (derived, I think, from the Carthaginian)" (p. 78, nn. 89, 90). At still other moments, Kepler offers geometric proof and rhetorical exposition; he refers readers to other scholarly literature, as well as to specific observational experiences.

In this context, Kepler's notes to the text problematize any relationship between reading and observing. When he discusses the origin of the Dream, Kepler insists that his work precedes observational studies conducted by others, as well as his own reading in classical sources. In keeping with this argument, Kepler describes the intellectual affiliation he sees between his writing on the moon and that in Lucian's A True Story and Plutarch's On the Face Which Appears in the Orb of the Moon ${ }^{36}$ Kepler remembers the way in which Erasmus Reinhold's commentaries led him to Plutarch and how he found a copy of Lucian at a Prague bookseller's in 1604 (pp. 30-35, n.2). These details provide a history of reading in classical sources that would seem implicitly to authorize Kepler to write on this topic. They offer a 
philological annotation comparable to Kepler's decision to append his own Latin translations of these two texts to the Dream. ${ }^{37}$ Yet, even as Kepler presents himself as an expert reader - one able to translate classical texts into his own language and intellectual situation - he also asserts that the Dream supersedes such scholarly reading. Kepler thus paradoxically concludes by noting that he was "exceedingly amazed" that his ideas corresponded so closely with Plutarch's "because they did not all come to me from reading this book" (p. 32, n. 2).

If Plutarch and Lucian are logical sources for any study of the moon that depends on a text-based humanism, Galileo is correspondingly prominent in an observationally-oriented astronomy of the seventeenth century. It is not surprising, then, that Kepler directs attention to the new methods of observation that the telescope made possible for Galileo but then asserts, here again, that it was not the telescope that gave him the knowledge contained in his Dream. Kepler contends, for example, that the moon has both high mountains and extensive valleys (p. 27). Galileo had begun his Sidereus nuncius (1610) by asserting that the moon is not smooth, but "rough and uneven ... crowded everywhere with vast prominences, deep chasms, and convolutions." 38 This provocative introduction became particularly widely known because, while Galileo's other claims proved notably difficult to confirm, the new surface of the moon was comparatively easy to see "with the certainty of the senses." 39 Mentioning neither Galileo nor his Sidereus nuncius, Kepler tersely notes that his own arguments about the nature of the moon are "older than the Dutch telescope" (p. 125, n. 207). Even as he makes these assertions, Kepler's text elsewhere gives other, conflicting accounts for the sources of these ideas. ${ }^{40}$ To point out these tensions in the text is not to attribute to Kepler a form of professional jealousy analogous to Galileo's. Rather, what Kepler struggles with in notes like these is the relationship between apprehending and comprehending. His notes reproduce the subject of the Dream in suggesting that true knowledge is a kind of utopia that exceeds both reading and observation as necessarily limited acts of seeing.

In Kepler's text, the movement to the moon involves a transition from the "fiction" of the frame narrative to the displaced scientific "truth" of the central narrative. Following a tradition familiar from More's Utopia, Kepler imagines a difficult passage to the center of the text: leaving Iceland for knowledge of the moon, Fiolxhilde invokes the daemon spirit through "ceremonies" in which the travellers utter incantations and cover their heads with their clothing (p. 14). Kepler glosses this liminal moment in the text 
with a long note about a similar "ceremony" that he used when conducting his observations in Prague. When visitors came to see his observations, he introduced them to his work by a secret demonstration:

I cut out the daylight ... and hung a white sheet on the wall. ... In capital letters I wrote with chalk on a black board what I thought suited the spectators. The shape of the letters was backwards (behold the magical rite), as Hebrew is written. I hung this board with the letters upside down in the open air outside in the sunshine. As a result, what I had written was projected right side up on the white wall within. (p. 57, nn. 44, 46, 47)

In her analysis of Kepler's optical treatises, Svetlana Alpers has shown how Kepler's interest in the pinhole camera was part of a new visual culture that came to dominate Northern Europe. Kepler no doubt creates this mysterious demonstration with his room-sized pinhole camera to display his mastery over the elements of light. ${ }^{41}$ As Alpers concludes, Kepler attributes "the enigma of the astronomical observations to the deception of vision." 42 In the context of the Dream, however, this story provides not simply an optics demonstration but, more specifically, a consideration of how reading and observing intersect as acts of seeing. Kepler's "demonstration" transforms what begins as a "certain act of observation" into a form of reading. Looking through the pinhole camera inverts the cryptic images and so literally translates what seems as foreign as Hebrew into a legible script written for the watching audience. Kepler introduces this account of the "reading" of these observations at this point in the Dream as a way of structuring the "translation" of his readers to the moon.

Whereas the notes and frame narrative identify a conflict between observation and reading as the key problem of modern knowledge, the utopia at the heart of Kepler's narrative imagines a world that reconciles this conflict through its physical reality. The utopic central section inverts the normal situation, in which we make claims about the earth based on our observations of the moon. Kepler asks us instead to imagine being on the moon while looking back at the earth. As the work of Alexander Koyré and others has long made clear, Kepler's adherence to a comparatively traditional cosmography is signaled by his refusal to consider seriously the possibility of an infinite universe. ${ }^{43}$ An important corollary to Kepler's adherence to the idea of a finite universe is that Kepler does not anticipate the modern recognition that in astronomy there is no privileged observer, no "determinate places." 44 Man may not be at the center of the universe, but for Kepler he nonetheless remains central to it. As Kepler explains in The Secret of the Universe, "From the love of God for Man a great many causes of the features 
of the universe can be deduced. ... For the end of both the universe and the whole creation is Man." 45 Yet, at the same time, Kepler is also able to imagine seeing the "whole creation" from other vantage points in the cosmos.

Imaginatively augmenting the limitations of human knowledge, such vantage points become a productive fictional proposition for Kepler. In The Secret of the Universe, for instance, Kepler responds to dispute about the thickness of the spheres by suggesting that a physicist cannot answer this question unless "the test of observation and the agreement of the hypotheses has transported him out to the actual sky and between the spheres." 46 What is in this case a rhetorical gesture becomes in The New Astronomy a method for determining the orbit of Mars. As a number of readers have recognized, Kepler's discovery of the orbit of Mars depended on rethinking the subject from, literally, a new perspective: having "transposed his eyes" to a position in Mars's orbit enables Kepler to solve a notoriously difficult astronomical problem. ${ }^{47}$ The basic fictional premise of the Dream - imagining how the earth and by extension "the whole creation" would appear from the moon - is thus anticipated by Kepler's more serious astronomical work.

While in The Secret of the Universe and The New Astronomy these tentative and hypothetical "displacements" of man become a way of producing new knowledge, the Dream in some sense alters our physical and cognitive perspective in order to create fictions. In making this claim, I am not suggesting that what separates Kepler's Dream from his more truly and truthfully "scientific" works comes down to a distinction between fact and fiction. Following Marjorie Hope Nicolson, readers of the Dream have emphasized how after the "fantasy" of the frame narrative, the central description of the moon is almost strictly "scientific": however curious the form, what Kepler has written seems to be "an astronomical treatise."48 Yet Kepler also encourages us to recognize that the primary purpose of the Dream is not to tell truths, convey scientific facts, or discover new knowledge. Rather, the Dream is about transforming what we have always understood to be truth into fiction.

Kepler's references in The Secret of the Universe to philosophers being "transported" out to the celestial spheres ironically recalls the resistance that men such as Cesare Cremonini, Christopher Clavius, and Guilio Libri had to the telescope. Frustrated at those who refused even to look through the telescope, Galileo famously turned jokes about the telescope back against his adversaries: when Libri, for instance, died without ever having looked through the telescope, Galileo mockingly expressed the hope that Libri 
would now have a chance to see the Medicean stars on his way to heaven. ${ }^{49}$ Kepler responds to these attacks on the telescope in a somewhat different fashion: the kind of joke that Galileo's opponents use to dismiss the telescope becomes in Kepler the narrative premise of the Dream. Kepler comments on Fiolxhilde's conversations with daemons by remarking, "There is a popular joke: 'I'll believe it rather than go into the matter personally'" (pp. 14 and 53, n. 41). Recognizing how Galileo's observations alter theories about the presence of water on the moon, Kepler suggests, "Let us believe this for the time being until some explorer goes into the matter in person" (p. 124, n. 202). To correct an earlier claim, Kepler comments, "See how anxiously I worry about correcting my statements lest some recent observer of these phenomena come down from the moon and prove me wrong" (p. 118, n. 188). When Libri dismissed Galileo and the telescope, he implicitly asserted that these new "observations" were nothing more than fictions. ${ }^{50}$ Kepler in the Dream makes his readers take the imaginative trip that Libri refused to consider. Yet he does not do so to confirm the truth of Galileo's observations or even Copernicus's theories. Instead, in what Kepler identifies as "the thesis of this book," the Dream demonstrates that what we had always relied on as the truth was only a fiction:

what are for us among the main features of the entire universe: the twelve celestial signs, solstices, equinoxes, tropical years, sidereal years, equator, colures, tropics, arctic circles, and celestial poles, are all restricted to the very tiny terrestrial globe, and exist only in the imagination of the earth dwellers. Hence, if we transfer the imagination to another sphere, everything must be understood in an altered form. (p. 85, n. 105; emphasis added)

Responding to the way in which science changed man's knowledge of the universe, Kepler would also have us alter our imaginations. Kepler ultimately uses this strategy of making us see the world differently to return to what is, in important ways, a more traditional understanding of man's place in the universe.

Eloquently describing the cognitive shift that Kepler confronts, Max Caspar describes the new intellectual vantage point that Copernican astronomy brought:

Formerly the desire had been to comprehend nature from within, or, if you like, from above as a whole... . Now men's eyes were turned to the fullness of the facts. ... If man had previously looked down, as it were from the other world upon the earth and the whole material world, he now placed himself inside of things and looked from these up to the heaven. ${ }^{51}$ 
An appropriate illustration of the first of these attitudes can perhaps be seen in Peter Apian's often reprinted cosmography handbook. The first page of the 1544 Cosmographie de Pierre Apian defines cosmography with an image of the sphere of the fixed stars. Although earlier editions of Apian's handbook illustrated cosmography with the image of an "eye" looking up at the earth and the heavens around it, the 1544 edition inverted this illustration. By depicting a celestial "eye" looking down on the earth, Apian's frontispiece makes explicit the philosophical assumptions inherent in the cosmography that Kepler inherited. As Caspar suggests, philosophers such as Apian understand cosmography as a form of study that symbolically comprehends the earth's position in the larger universe through what Caspar describes as a looking down "from above as a whole." 52 Familiar with the Cosmographie, Kepler elsewhere dismisses both Apian's scientific theory and practice as a "pathetic diligence" that labored to represent fictions of "that which exists only in the mind." 53 In the fictional world of the Dream, however, Kepler creates a selenography that looks back critically at cosmographies such as Apian's. Kepler's lunar astronomy invokes the telescope, not just as a new technology, but as a way of imaginatively recapturing the sense that earlier astronomers had of being able to look down upon the earth with knowledge and certainty.

Recognizing that under a Copernican model man is not the measure of his universe, Kepler postulates a world where the Levanians are the measure of their universe. Kepler depicts the inhabitants of Levania as fantastically embodying the physical reality of their world. Having both a "monstrous size" and a "short life," the physical being of these creatures expresses the "proportion" of the astronomical circumstances of their world (p. 27). In so depicting them, Kepler also emphasizes how man is in important ways physically inadequate to apprehend other worlds. Kepler imagines how those who might attempt to investigate the world of Levania would risk the "greatest danger to life" to the point of being almost "torn to pieces" (pp. 15 and $71, \mathrm{n} .68$ ). If the realm of the moon remains critically unknowable to man, the Levanians need neither books nor telescopes to know their world. Unlike man, they possess a relationship to their physical environment that allows them direct and unmediated access to knowledge. Even as Kepler purports to be demonstrating the Copernican theory, he represents the Levanian world through a fundamentally pre-Copernican understanding of man. 
Kepler's Dream projects a world in which knowledge is based on direct observation in a way not physically possible on earth. ${ }^{54}$ In trying to portray what the earth looks like from the moon, Kepler renames these celestial bodies to accord with the way this change in perspective also alters how they appear to observers. The moon that we see primarily as white becomes Levania ("lebhana," "luna," "selene"), while the earth that they perceive as rotating is for them the Volva ("volvere") (p. 78, $\mathrm{nn} .89,90$ ). The universe as they experience it is dominated by the Volva, which "remains fixed in place, then, as though it were attached to the heavens with a nail" (p. 22). Because the earth is four times the diameter of the moon, the Volva thus appears on their horizon fifteen times larger than the moon does on ours (p. 21). For that part of Levania which faces towards the Volva, the view of the Volva provides "the most beautiful of all the sights" (ibid.); the hemisphere forever turned away from the Volva becomes a realm of complete "indigence and loneliness" (p. 107, n. 149). ${ }^{55}$ The appearance of the Volva becomes important to the inhabitants of Levania as a source of knowledge as well as beauty. The constancy of the Volva means that this world has natural solutions to key epistemological problems confronted by early modern philosophers. Simply looking at the Volva - without books, calculations, or artificial observations - enables the Levanians to ascertain their "situation" in the world with a confidence not possible on earth (p. 97, n. 132). By providing a means for determining longitude, telling time, and tracking the seasons, the Volva provides a physical sign within the utopia of the truth that eluded the readers and observers of Kepler's world.

The problem of longitude was one that Kepler's original readers would have understood as almost mythically unsolvable. Philosophers had of course long recognized that solving this problem depended on finding or establishing a reference point from which to observe the universe. Astronomers such as Philip Apian and Guillaume de Nautonier, for instance, tried to establish such a point within the planet itself by looking for regular declination from the magnetic pole (pp. 98-101, n. 134). 56 Yet, as Kepler recognized, neither this answer nor others proposed ever went beyond "very laborious and uncertain method" (p. 98, n. 134). Whereas on earth "we have nothing but that most lowly and barely perceptible declination of the magnet" as a possible guide to finding longitude, the Levanians can chart longitude by referring to their positions relative to the Volva. The "barely perceptible" motions of the magnet on which astronomers depended are corrected on Levania by the motionlessness of the Volva. At central longitudes, the Volva 
appears high in the sky, visibly "brilliant" (p. 22); as one travels around Levania to outer longitudes, the Volva becomes like "a mountain on fire far away" (p. 21).

Kepler's utopia likewise avoids contemporary difficulties associated with accurate time-keeping because the enormous size of Volva ensures that for the Levanians time is always known. ${ }^{57}$ The Volva becomes an astrological clock, as its phases (new, first quarter, full, last quarter) mark the passage of the day from noon to morning light (p.23). Determining the precise hour itself requires only an attention to the appearance of the Volva, since it displays "a wonderful variety of spots" as it turns (ibid.). The panoramic succession of images produced by the Volva becomes a kind of moving story in the sky:

it looks like the front of the human head cut off at the shoulders [Africa] and leaning forward to kiss a young girl [Europe] in a long dress [Sarmatia, Black Sea regions], who stretches her hand back [Britain] to attract a leaping cat [Scandinavia]. (pp. 24 and 114, nn. 158-62)

In the world of human history that frames Kepler's Dream, Europe appears as a map of geopolitical "revolutions": thus it is the current uprising against Emperor Rudolph that leads Kepler's narrator to study the legendary revolt against the Bohemian ruler Libussa (p. 11). As Africa reaches out every hour to "kiss" Europe, the situation in Europe and adjacent regions appears quite different when seen from Levania. The political "revolutions" that Kepler alludes to at the start of his Dream have in Levania become a series of astronomical "revolutions" that produce constancy and stability by giving "the only uniform measure of time" (p. 23).

If what we experience as the geopolitical inconstancy of our world becomes from the moon a pleasing display in the sky, Kepler also uses the Levanians to rethink our equally troubled apprehension of the skies. By imagining the Levanians watching the "wonderful variety" of spots in their sky, Kepler distinguishes how they see the universe from the way that contemporary observers on earth responded to different kinds of "variety" in the heavens. Mostly notably, Kepler here invokes reaction to Galileo's claims of having with the telescope seen "large spots" on the face of the moon and the surface of the sun. ${ }^{58}$ Reports from Galileo and others of such "spots" transformed what had before been "pure," "smooth," and "unchanging" celestial bodies into objects as potentially transient as anything on earth. At the same time, "displays" created by new comets produced another type of uncertainty: Kepler, having twice published on this topic, certainly 
remembered the fiery 1618 comet which "appeared as though an aristocratic young lady was driving along in a coach." 59 As viewed from earth, the panorama of the skies seemed to be a sign of uncertainty, indicating disturbing mutability in the heavens or predicting a catastrophic future on earth. "Wonderful" and "uniform," what the Volvans instead see is a story that reassuringly repeats itself every twenty-four hours: each new attempt by the man to kiss the girl marks another hour for them. Kepler's watching Levanians in some sense become their own internal clock because their position as observers makes them integral to the knowledge they produce. Requiring neither telescopes nor books to know their world, the Levanians enjoy the "measure" no longer possible in Kepler's post-Copernican astronomy.

Emphasizing how the knowledge of the Volva is apparent "to anyone who is observant," Kepler suppresses facts that do not support a radical connection between seeing and knowing (p. 24). Kepler avoids noting, for instance, that finding the latitude on Levania would be nearly as difficult as finding the longitude is on earth. He alludes to the latitude problem only to show how "convenient" the Volva is for determining longitude on Levania (p. 22). While the correlation between the earth's longitude and Levania's latitude is passed over here, Kepler elsewhere emphasizes the comparable connection between the earth's latitude and Levania's longitude. He does so because this connection can be assimilated into his argument concerning the visible knowledge of Levania. Kepler accordingly likens the Volva's presence on the horizon to the altitudes of the pole, "even though we do not see the pole itself with our own eyes" (ibid.). The most logical terrestrial analogue to the Volva's "always visible" presence on the Levanian horizon would be the star Polaris at the North Pole. As a real and visible natural body, Polaris provides information about location on earth in much the same way that the Volva would on the moon. Instead of discussing the Pole star, however, Kepler's narrative emphasizes the Pole, an abstract (and invisible) concept. In making these narrative choices, Kepler thus reiterates that the Levanian world can be apprehended immediately and intuitively in ways that our world cannot.

Knowledge, for the Levanians, is a physical consequence of their position in the universe. As Hans Blumenberg emphasizes, most astronomical discoveries after Galileo were a consequence of the advantages that resulted from man's eccentric position in the universe: what we on earth know is in large part attributable to the fact that, not being at the center, we 
can see at an angle. ${ }^{60}$ Kepler uses his fiction to take advantage of a more extreme shift in perspective. While on earth we rely on the "laborious and uncertain" evidence provided by the sun and fixed stars, the Levanians look only to the Volva. Physically dominating their experience of the universe, the Volva provides beauty, knowledge, and constancy for them. That is, by imagining the experience that the Levanians have of our earth, Kepler has in some sense found a perspective from which we are indeed the measure of the universe. Even as Kepler uses his fiction to demonstrate the world system that physically moves man to the periphery, he allows the earth to be for the Levanians what it cannot be to us on earth. Recognizing the conflict in a desire to integrate traditional reading practices with new observational methods, Kepler imagines a world in which neither reading nor observation is necessary. In the end, Kepler's utopic Dream admits the physically necessary limitations to human knowledge in order to project a world and place without such limitations.

Texas Christian University

\section{Notes}

1. Letter to Matthias Bernegger, 4 December 1623, in Carola Baumgardt, ed. and trans., Johannes Kepler: Life and Letters (New York: Philosophical Library, 1951), pp. 155-56.

2. Johannes Kepler, "Original Preface to the Reader," in Mysterium Cosmographicum: The Secret of the Universe, trans. A. M. Duncan and ed. E. J. Aiton, with a preface by I. Bernard Cohen (New York: Abaris Books, 1981), p. 69.

3. Kepler's son, Ludwig, ultimately published the book under the title Ioh. Keppleri; Mathematici olim Imperatori Somnium, seu Opus Posthumum de Astronomia Lunari. References throughout are to Johannes Kepler, Somnium: The Dream, or Posthumous Work on Lunar Astronomy, ed. and trans. Edward Rosen (Madison: University of Wisconsin Press, 1967); unless otherwise specified, references to note numbers indicate Kepler's own textual notes.

4. On the textual history of the Dream, see Rosen, ed. and trans., Introduction, pp. xvii-xxi.

5. Louis Marin, Utopics: Spatial Play, trans. Robert A. Volrath (Atlantic Highlands, NJ: Humanities Press, 1984), pp. 33-60.

6. Fredric Jameson, "Of Islands and Trenches: Neutralization and the Production of Utopian Discourse," in The Ideologies of Theory: Essays 1971-1986, 2 vols. (Minneapolis: University of Minnesota Press, 1988), 1: 75-101.

7. Marina Leslie, Renaissance Utopias and the Problem of History (Ithaca, NY: Cornell University Press, 1998), p. 2. Leslie's model importantly recognizes and attempts to account for the almost perverse way that the utopia is generically unstable because it internalizes its 
commitment to reform; understood in this manner, utopia is less a fixed genre than a writing practice that enacts a self-conscious need to rewrite earlier utopias.

8. Richard Rorty, Philosophy and the Mirror of Nature (Princeton, NJ: Princeton University Press, 1979), p. 159.

9. Ibid., p. 160.

10. Anthony Grafton, “Kepler as a Reader," Journal of the History of Ideas 53 (1992): 565.

11. J. V. Field, Kepler's Geometrical Cosmology (Chicago: University of Chicago Press, 1988), pp. 163-67, 172-76.

12. Grafton, "Kepler as a Reader," pp. 565, 563. For two excellent accounts, from different perspectives, of the importance of reading as a practice in the development of early modern science, see Anthony Grafton, Defenders of the Text: The Traditions of Scholarship in an Age of Science, 1450-1800 (Cambridge, MA: Harvard University Press, 1991), and William H. Sherman, John Dee: The Politics of Reading and Writing in the English Renaissance (Amherst: University of Massachusetts Press, 1995), pp. 29-52, 79-100.

13. Louis Marin, "Toward a Semiotic of Utopia: Political and Fictional Discourse in Thomas More's Utopia," in Richard Harvey Brown and Stanford M. Lyman, eds., Structure, Consciousness, and History (Cambridge: Cambridge University Press, 1978), p. 266.

14. For central arguments about the symbolic importance of the telescope in defining new models of knowledge, see Timothy J. Reiss, The Discourse of Modernism (Ithaca, NY: Cornell University Press, 1982), pp. 31-33, and Hans Blumenberg, The Genesis of the Copernican World, trans. Robert M. Wallace (Cambridge, MA: MIT Press, 1987), pp. 617-74.

15. Marjorie Hope Nicolson, "Kepler, the Somnium, and John Donne," Journal of the History of Ideas 1 (1940): 276-77; Frank E. Manuel and Fritzie P. Manuel, Utopian Thought in the Western World (Cambridge, MA: Harvard University Press, 1979), p. 212; and Joseph Keith Lane, ed. and trans., "The Dream, or Posthumous Work on Lunar Astronomy" (M.A. thesis, Columbia University, 1947), p. vii.

16. See Nicolson, "Kepler," pp. 260-67; Arthur Koestler, The Sleepwalkers: A History of Man's Changing Vision of the Universe (New York: Macmillan, 1959), p. 419; and John Lear, ed., Kepler's Dream, trans. Patricia Frueh Kirkwood (Berkeley: University of California Press, 1965), pp. 17-18, 21.

17. Max Caspar, Kepler, trans. and ed. C. Doris Hellman (New York: Abelard-Schuman, 1959), pp. 240-58.

18. When Kepler alludes to works such as Martin del Rio's Investigation of Magic (1599-1600), for instance, he presents himself as knowledgeable about key texts and controversies surrounding contemporary discussions of witchcraft (p. 50, n. 34).

19. Letter to Matthias Bernegger, 4 December 1623, cited in Baumgardt, p. 155.

20. Caspar, pp. 254-55.

21. Grafton, "Kepler," p. 563.

22. Steven Shapin and Simon Schaffer, Leviathan and the Air-Pump: Hobbes, Boyle, and the Experimental 'Life (Princeton, NJ: Princeton University Press, 1985), pp. 60-65. 
23. Kepler's Secret of the Universe, e.g., was listed for sale at the 1597 Frankfurt Book Fair (Caspar, p. 69). On the literary and intellectual culture that Kepler was a part of in Rudolphine Prague, see Anthony Grafton, "Humanism and Science in Rudolphine Prague: Kepler in Context," in James A. Parente, Jr., Richard Erich Schade, and George C. Schoolfield, eds., Literary Culture in the Holy Roman Empire, 1555-1720 (Chapel Hill: University of North Carolina Press, 1991), pp. 19-45, and the definitive work of R. J. W. Evans, Rudolph II and His World: A Study in Intellectual History, 1576-1612 (Oxford: Clarendon Press, 1973), pp. 243-74.

24. Hans Raeder, Elis Strömgren, and Bengt Strömgren, trans., Tycho Brahe's Description of his Instruments and Scientific Work (Copenhagen: Ejnar Munksgaard, 1946). On Brahe's years at Uraniborg, see Victor E. Thoren, The Lord of Uraniborg: A Biography of Tycho Brahe, with contributions by John R. Christianson (Cambridge: Cambridge University Press, 1990), pp. 105-219, 334-75.

25. On Libavius's critique of Brahe in his Alchymiae (1606), see both Owen Hannaway, "Laboratory Design and the Aim of Science: Andreas Libavius versus Tycho Brahe," Isis 77 (1986): 585-610, and the reassessment by Jole Shakelford, "Tycho Brahe, Laboratory Design, and the Aim of Science: Reading Plans in Context," Isis 84 (1993): 211-30. As Thoren suggests of Brahe and Hannaway of Libavius, both Uraniborg and the unrealized Chemical House proposed by Libavius are strongly influenced by Vitruvian architectural theory (Thoren, pp. 106-8; Hannaway, pp. 599-602); see further, Rudolf Wittkower, Architectural Principles in the Age of Humanism (1949; rpt. New York: St. Martin's Press, 1988), pp. 1-28.

26. Hannaway, p. 605.

27. Caspar, pp. 99-123; Thoren, pp. 432-42, 450-53.

28. Thoren, pp. 185-87.

29. In a compelling study that places utopia in the context of early modern institutional organization, Amy Boesky compares Uraniborg to John Dee's library at Mortlake, Cornelius Drabbel's laboratory at Eltham Palace, and Rudolph's Prague Academy as a physical realization of the utopian ideal of learning expressed fictionally in Bacon's New Atlantis (pub. 1627) (Founding Fictions: Utopias in Early Modern England [Athens, GA: University of Georgia Press, 1996], pp. 56-61).

30. Reiss, pp. 23, 144. For an engaging discussion of the historical development of footnotes, see Anthony Grafton, The Footnote: A Curious History (Cambridge, MA: Harvard University Press, 1997).

31. Kepler, Mysterium Cosmographicum, p. 39.

32. Ibid., p. 35 .

33. Field, pp. 30-44.

34. I. Bernard Cohen, for instance, describes the 1621 edition as "notable" for its inclusion of Kepler's second thoughts (Preface to Kepler, Mysterium Cosmographicum, p. 7); observing that some of Kepler's notes are "rather brutal," Field likewise demonstrates that the notes show "which points Kepler believed were important - in 1596, 1621, or both" (p. 34). Field also elegantly elucidates the intellectual development between the two versions, with separate chapters on each edition (pp. 30-72, 73-95). 
35. Kepler, Mysterium Cosmographicum, p. 41.

36. Lucian, A True Story, in A.M. Harmon, ed. and trans., Lucian, 8 vols. (Cambridge, MA: Harvard University Press, 1953), 1: 248-357; Arthur O. Prickard, ed. and trans., Plutarch, On the Face Which Appears on the Orb of the Moon (Winchester: Warren, 1911).

37. The Dream was, at Kepler's request, published jointly with his translation of Plutarch into Latin; James S. Romm discusses a letter from Kepler to Matthias Bernegger that indicates that Kepler originally hoped to include with them an edition of Lucian's A True Story ("Lucian and Plutarch as Sources for Kepler's Dream," Classical and Modern Literature, 9 [1989]: 101). Romm concludes that Kepler emphasizes the most self-consciously fictive moments of Plutarch and Lucian's work. In doing so, Kepler attempts to reconcile a traditional understanding of reading associated with philological scholarship with the new kinds of knowledge being discovered through the telescope.

38. Galileo Galilei, Sidereus nuncius, or, The Sidereal Messenger, ed. and trans. Albert van Helden (Chicago: University of Chicago Press, 1989), p. 36.

39. Ibid.

40. See, e.g., p. 124, n. 202; p. 129, n. $211 ;$ p. 54, n. 43.

41. Svetlana Alpers, The Art of Describing: Dutch Art in the Seventeenth Century (Chicago: University of Chicago Press, 1983), pp. 26-41. For an introduction to Kepler's contributions to seventeenth-century optics and the new "visual" culture that Kepler helped define, see David C. Lindberg, Theories of Vision from Al-Kindi to Kepler (Chicago: University of Chicago Press, 1976), pp. 178-208; Thomas DaCosta Kaufmann, The Mastery of Nature: Aspects of Art, Science, and Humanism in the Renaissance (Princeton, NJ: Princeton University Press, 1993); and Edward G. Ruestow, The Microscope in the Dutch Republic: The Shaping of Discovery (Cambridge: Cambridge University Press, 1996).

42. Alpers, p. 34.

43. Alexandre Koyré, From the Closed World to the Infinite Universe (Baltimore: Johns Hopkins University Press, 1957), pp. 58-87.

44. Johannes Kepler, De stella nova (1606), cited in Koyré, p. 61.

45. Kepler, Mysterium Cosmographicum, p. 107.

46. Ibid., p. 155.

47. Caspar, p. 130; see also Koestler, pp. 324-25, and, for a lucid technical explication, Bruce Stephenson, Kepler's Physical Astronomy (Princeton: Princeton University Press, 1987), pp. 21-39.

48. Marjorie Hope Nicolson, Voyages to the Moon (New York: Macmillan, 1948), p. 45; Lane, p. vii.

49. Mario Biagioli, Galileo Courtier: The Practice of Science in the Culture of Absolutism (Chicago: University of Chicago Press, 1993), p. 169.

50. In his prominent attack on Galileo, Martin Horky used precisely this kind of language when he asserted to Kepler that not only were the satellites of Jupiter "fictitious" but the whole account was nothing more than "a fable" (letter to Johannes Kepler, 27 April 1610, cited in Albert van Helden, "Telescopes and Authority from Galileo to Cassini," Osiris 9 [1994]: 11). For assessments of both the initial resistance to the telescope and subsequent acceptance 
of it, see especially Blumenberg, pp. 642-74; van Helden, "Telescopes and Authority," pp. 9-29; Paul Feyerabend, Against Method: Outline of an Anarchistic Theory of Knowledge (London: Verso, 1978); and Biagioli, p. 96, n. 296.

51. Caspar, p. 18.

52. Ibid. The inverted illustration in La cosmographie de Pierre Apian (Antwerp, 1544) can be compared, e.g., to a version of the original in Cosmographicus liber Petri Apiani mathematici (Antwerp, 1533).

53. Kepler, New Astronomy, cited in Koestler, p. 319.

54. Alpers identifies Kepler as someone who recognizes that distortion is inherent in any lens - whether the lens of the eye or the telescope. She concludes that Kepler defends the use of optical tools not so much by arguing for their integrity as by demonstrating that natural vision is characterized by a similar distortion, the "deception of vision." As a utopia, the Dream avoids the need to reconcile natural and artificial observation, since it imagines a world without man and, in consequence, also without his fallenness (Alpers, pp. 34-35).

55. Kepler often refers more specifically to the inhabitants of these two hemispheres as, respectively, Subvolvans and Privolvans. In keeping with Kepler's understanding of the Volva as the defining feature of this world, the Privolvans, who never get to see the Volva, largely disappear from the narrative. To avoid confusion, I will refer collectively to the inhabitants of Levania, even though many of Kepler's remarks would truly apply only to the inhabitants of the near side, the face, of the moon.

56. Derek Howse, Greenwich Time and the Discovery of the Longitude (Oxford: Oxford University Press, 1980).

57. David S. Landes, Revolution in Time (Cambridge, MA: Harvard University Press, 1983), pp. 84, 132, 145.

58. Galileo, Sidereus nuncius, p. 43, and "The Sunspot Letters," in Stillman Drake, ed. and trans., Discoveries and Opinions of Galileo (Garden City, NY: Anchor Books, 1957), p. 92.

59. Caspar, p. 301. See Stillman Drake and C. D. O'Malley, eds. and trans., The Controversy on the Comets of 1618: Galileo Galilei, Horatio Grassi, Mario Guiducci, Johann Kepler (Philadelphia: University of Pennsylvania Press, 1960).

60. Blumenberg, p. 630. 